\title{
CONSTITUCIONALISMO CONTEMPORÂNEO E CONSTITUIÇÃO FICCIONAL FUNDADORA: O CARÁTER CONSTRUTIVO E FICTÍCIO DAS INTERPRETAÇÕES À LUZ DA MATRIZ DIREITO- LITERATURA
}

CONTEMPORARY CONSTITUTIONALISM AND FOUNDER FICTIONAL CONSTITUTION: THE CONSTRUCTIVE AND FICTIOUS CHARACTER OF INTERPRETATIONS IN THE LIGHT OF MATRIX LAW-LITERATURE

"Os poetas são os legisladores desconhecidos do mundo"

(Percy Shelley, Uma defesa da poesia e outros ensaios)

Henriete Karam

Angela Araujo da Silveira Espindola

\section{RESUMO}

Centrado na temática "constitucionalismo e literatura", inserido no contexto das reflexões da Constituição Balzaquiana e vinculado à matriz direito-literatura como referencial teórico e, simultaneamente, como metodologia de abordagem, com incursões na fenomenologia hermenêutica e na psicanálise, este artigo funde olhares jurídicos, e literários, para construir a Constituição de 1988 e narrar o constitucionalismo contemporâneo, descrevendo a Constituição não como lei fundamental, mas antes como Constituição ficcional fundadora, que é também filtro de narratividade para a interpretação constitucional. 
Palavras-chaves: constitucionalismo contemporâneo. Direito e literatura. Imaginário jurídico. Constituição fundadora. Constituição ficcional. Filtro de narratividade.

\section{ABSTRACT}

This article discusses merging law and literature, in the light of constitucionalism and narratives to construct the Constitucion of Brazil and talk about contemporary constitutionalism, describing the Constitucion not as a fundamental law, but rather as a fouding fictional constitucion, which i also a narrative filter for constitucional.

Keywords: contemporary constitutionalism, law and literature, legal imaginary, founding constitution, fictional constitution, narrative filter

\section{CONSIDERAÇÕES PRELIMINARES}

Há sempre muitas formas de contar uma história, assim como há tantas outras para recontá-la. Tais assertivas aplicam-se - como não poderia deixar de ser - também à história do constitucionalismo, sendo bastante comum que, nas diferentes narrativas produzidas, $o$ constitucionalismo encontre-se associado a uma forma de limitação do poder do Estado e, simultaneamente, a uma forma de afirmação da soberania do Estado.

Na tentativa de compreender o constitucionalismo contemporâneo ${ }^{1}$, é importante debruçar-se sobre o papel e o sentido do constitucionalismo e da Constituição. E aí reside o primeiro desafio: constitucionalismo é um conceito nebuloso e, talvez, ainda não absolutamente consolidado ${ }^{2}$.

Para Canotilho (2003, p. 51), o constitucionalismo "é a teoria (ou ideologia) que ergue o princípio do governo limitado indispensável à garantia dos direitos em dimensão estruturante da organização políticosocial de uma comunidade". Segundo ele, o constitucionalismo moderno representa "uma técnica específica de limitação do poder com fins garantísticos", transportando "claro juízo de valor" (CANOTILHO, 2003, p. 51). De tal modo que o constitucionalismo é, "no fundo, uma teoria 
normativa da política, tal como a teoria da democracia ou a teoria do liberalismo" (CANOTILHO, 2003, p. 51) ${ }^{3}$.

Seguindo essa trilha - de modo bastante abreviado, aliás -, constatase que esse movimento limitador e organizador, ao dar origem aos poderes constituinte e constituído, gera uma estrutura na qual se funda tanto o Estado quanto à concepção de cidadania que também o funda e vem expressa na Constituição.

Com tais premissas, incontáveis poderiam ser os direcionamentos desteartigo: desdeo (necessário) tensionamento entre o constitucionalismo e a democracia ${ }^{4}$ - esta como governo soberano do povo, o "governo da maioria", e aquele como o primado da lei, da Constituição, o "governo da minoria" -, passando pelos marcos teóricos do constitucionalismo até chegar às releituras e desleituras do constitucionalismo, bem como na crítica ao neoconstitucionalismo ${ }^{5}$ e na necessidade de construir espaços para a superação do pós-positivismo. Sem falar, ainda, nas reflexões possíveis sobre as tendências contemporâneas do constitucionalismo latino-americano.

O objetivo deste artigo, no entanto, é mais pontual, qual seja, investigar a contribuição da matriz direito-literatura para se pensar o Estado e Constituição, Direito e Literatura, Poder e Linguagem, bem como o imaginário sócio-político-jurídico-constitucional que compõem um filtro de narratividade a partir da Constituição como ficção fundadora.

Para tanto, o texto foi estruturado em três partes: primeiramente, aborda-se a construção do Estado como ente imaginário e a Constituição fundadora, para então apresentar a dualidade entre a Constituição real e a Constituição folha de papel, abrindo espaço de reflexão para compreender o linguist turn e o narrative turn, a partir da ambiguidade entre Direito e Literatura, Poder e Linguagem. Nesse compasso, culmina-se para a compreensão, a partir da matriz direito-literatura, de que Estado e Constituição são entes imaginários, que constituem filtro de narratividade, não só para a construção do constitucionalismo contemporâneo, mas sobretudo para, na tensão entre as funções de conservação e de reformulação do intérprete, evidenciar o papel construtivo e fictício das intepretações do direito, o que só é possível a partir da chave direito-literatura. 


\section{O ESTADO COMO ENTE IMAGINÁRIO E A CONSTITUIÇÃO FUNDADORA: A CONSTRUÇÃO DE FILTROS DE NARRATIVIDADE}

A unidade do poder político não foi sempre explicada da mesma forma. Veja-se: para os jusnaturalistas contratualistas, o seu fundamento estava em um pacto social originário que fundava a pólis; nas monarquias absolutistas, o fundamento desse poder estava na pessoa do Rei, senhor único e exclusivo dos súditos (CANOTILHO, 2003). Paulatinamente, numa espécie de ideário protodemocrático-nacional, o fundamento do poder passa a centrar-se na soberania, primeiro da nação, depois do povo. De fato, o Estado Liberal, primeira versão do Estado de Direito, cuja nascente foi burguesa, adotava a mesma retórica de um Estado Absolutista, distinguindo-se tão somente pela fundamentação da soberania nas mãos do povo, e não mais no poder divino do monarca. De certa forma, mantinha-se, nessa transição política, o mito da subjetividade originária (povo, nação, Estado).

O Estado Liberal Mínimo representou, como dito, a primeira versão do Estado de Direito, concebido como aquele que funda suas atividades no direito (naquele momento histórico identificado com a lei). 0 direito no Estado Liberal, diz Roth (1996, p. 19-20), destinava-se à proteção dos indivíduos contra toda pretensão de interferência do Estado em sua vida privada: "Ele garante ao cidadão, com força se necessário, o uso e o respeito de suas liberdades privadas"; protegendo o direito de propriedade, da liberdade de comércio e de indústria, e da liberdade de contratar. Fundava-se, sobretudo, contra o direito do Estado e assegurava a regulação espontânea da sociedade (ROTH, 1996) ${ }^{6}$.

A autovinculação e a autolimitação jurídica do poder estatal, portanto, impôs-se cada vez mais, fomentando o movimento constitucionalista do século XIX, ou seja, a afirmação do caráter plenamente normativo da Constituição dos Estados, considerada instância jurídica superior, símbolo maior do poder soberano.

A partir desse momento, percorreu-se (e ainda se percorre) um tenso e intenso caminho até que se abandonasse (e abandone) o mito da subjetividade originária, transcendendo para a compreensão de uma 
plurisubjetividade ${ }^{7}$ do poder constituinte, capaz de efetivamente servir de base para a construção do imaginário de uma Constituição jurídicoformal e esta como narrativa ficcional fundadora. A fenomenologia do poder constituinte é quem estrutura a legitimidade da Constituição bem como de um constitucionalismo e da Democracia ${ }^{8}$.

O Estado Democrático de Direito insere-se exatamente nesse cenário de evolução do Estado Liberal para o Estado Social - evolução que agregou componentes ao conceito de Estado, mas também eliminou outros (BOLZAN DE MORAIS \& STRECK, 2019). Cada um desses modelos de Estado, ou versões do Estado de Direito, assim como os períodos históricos em que cada um deles se insere, resulta de transformações políticas e sociais que os precederam, mas também de suas antíteses atuais ${ }^{9}$.

0 Estado, portanto, está envolto por um imaginário políticoconstitucional (OST, 2005); e o constitucionalismo que o banha guarda em si uma tensão entre a tradição e a inovação, entre conservar e avançar, entre reproduzir o direito e produzir o direito. Uma tensão que funde tradição político-constitucional e a abertura às promessas e a um projeto de futuro possível.

O Estado, assim com o Constituição, na esteira do constitucionalismo contemporâneo, são entes imaginários, atuam muito mais como uma imagem, talvez performativa, promotora de transformações sócio-políticas e institucionais do que como resultado institucional (CASTORIADIS, 2000). Exatamente por isso, a própria estrutura formal do Estado está longe de cobrir todas as articulações de poder que se combinam na estrutura global da sociedade.

O Estado incorpora referências muito fortes da Constituição, não de qualquer Constituição, mas - no caso brasileiro - da Constituição de 1988, que hoje é a Constituição de 2019, amanhã será a Constituição de 2020 e assim sucessivamente, como partes de um romance em cadeia ${ }^{10}$. E, nesse caso, o vetor aponta para a expectativa de um Estado Democrático de Direito e seu imaginário político-constitucional.

0 direito não se contenta em "defender posições instituídas, mas exerce igualmente funções instituintes - o que supõe criação imaginária de significações sociais-históricas novas e desconstrução das significações instituídas que a ela se opõem" (OST, 2005, p. 19). 0 conflito diário que 
transforma novas interpretações e aplicações da lei, da constituição é, como refere Ost (2005), o imaginário jurídico. A Constituição, nesse tensionamento, exerce o papel fundador e estruturante necessário para harmonizar passado, presente e futuro e, portanto, constituir a sociedade. A Constituição, portanto, funciona com uma narrativa ficcional fundadora, um filtro de narratividade que, como ente imaginário, funda o Estado Democrático de Direito e é também fundada por ele, que é também um imaginário sócio-político-constitucional.

O grande desafio de compreendê-los - Estado e Constituição - como entes imaginários é reduzi-los a uma construção humana contingente, resultado de referenciais sociais que estão baseados em significações atribuídas pela sociedade em que estão inseridos (CASTORIADIS, 2000). Se assim é, a Constituição pode não ter a força que pensamos (ou gostaríamos) que ela tivesse enquanto ente imaginário fundacional e também como filtro de narratividade. Nesse caso, assumiríamos o risco de repactuarmos o pacto social a partir de outras fundações; e, então, a Constituição não mais constituiria, deixando de ser um filtro de narratividade.

O antídoto para este efeito colateral de compreendermos Estado e Constituição como entes imaginários é assumirmos a defesa da matriz direito-literatura ${ }^{11}$ como contributo para pensar a Constituição enquanto ficção fundadora.

\section{A CONSTITUIÇÃO FOLHA DE PAPEL E A CONSTITUIÇÃO REAL: A TENSÃO ENTRE NORMATIVIDADE E IMAGINÁRIO}

No contexto das comemorações pelos trinta anos da Constituição Brasileira, Jorge Douglas Price ${ }^{12}$, explora as qualificações "Constituição Balzaquiana", em alusão ao romance La femme de trente ans ${ }^{13}$, de Honore Balzac (1998), e "Constituição Favelada", em referência à narrativa Quarto de despejo: diário de uma favelada ${ }^{14}$, de Carolina de Jesus (2014), para abordar a distinção, proposta por Ferdinand Lassalle ${ }^{15}$, entre a Constituição "folha de papel" e a Constituição "real", e conclui que a 
Constituição decorre de uma prática comunicativa que a "refunda" incessantemente no imaginário social.

A partir daí, pode-se questionar qual o sentido de uma Constituição? Afinal, em se tratando de uma prática comunicacional, a Constituição tem seu conteúdo esvaziado e preenchido incessantemente, sendo inatingível um ponto fixo, estável, imutável. A Constituição é a lei fundamental, mas é, também, sobretudo fundacional - o que não significa que seja de um conceito absoluto e imutável, tampouco um texto completamente cristalizado. Para Canotilho, "Constituição é a ordenação sistemática e racional da comunidade política, através de um documento escrito no qual se declaram as liberdades e os direitos e se fixam os limites do poder político" (CANOTILHO, 1997, p. 52). Essa compreensão deriva da perspectiva dual estabelecida por Lassalle (2002) ao falar em Constituição real e Constituição folha de papel. A Constituição não pode se resumir a mero texto de lei, tal qual a Constituição folha de papel de Lassalle (2002, p. 39-42). Se, de um lado, a Constituição precisa externalizar-se como folha de papel, para ter validade e ajustar-se à Constituição real, de outro, a Constituição é, acima de tudo, o somatório dos fatores reais de poder que vigoram em dado país, em certo momento histórico (LASSALLE, 2002, p. 48), sem o qual ela deixa de ser uma Constituição fundacional.

Outra forma de apresentar essa dualidade é visualizando a Constituição diante do espelho: onde se localizam o real e sua representação. Real e representação não raro se confundem. É claro que o conceito de representação da realidade está longe de encontrar um consenso ao longo da história da filosofia. De Platão à Foucault, muitos enfrentaram o tema. Platão trata da representação da realidade em $A$ República, cujo trecho mais conhecido está no Livro VII (PLATÃO, 2006, p. 309-352): a alegoria da caverna. Há, no entanto, no Livro X, um diálogo entre Sócrates e Glauco sobre o objeto e a cópia, de onde se infere que, para Platão (2006), a representação do real pela arte é mera imitação, representação do mundo das aparências e das ideias. Em Platão, a imitação seria o distanciamento da verdade e o lugar da falsidade e da ilusão. Mas em Aristóteles (1997) o conceito se alarga, e a arte passa a ser relacionada à criação. 
Estamos tratando de ficção e realidade, da literatura e do direito, do imaginário e da normatividade. A par disso, podemos pensar na função de subversão crítica do imaginário social por meio da própria literatura (OST, p. 25). Para Ost, a literatura por vezes assume uma função de conversão fundadora e a narrativa faz-se fundadora (OST, p. 25).

Assumir a matriz direito-literatura, especialmente a perspectiva do Direito como Literatura, implica admitir uma possível articulação interna entre direito e literatura, de modo a descortinar notáveis analogias entre o processo de produção discursiva de Direito e Literatura, tomada em sentido amplo (CÁRCOVA, 2014, p. IX). Segundo Cárcova,

[...] law as literature (direito como literatura), se ocupa predominantemente de poner en juego categorías desarrolladas en los últimos cien años por la lingüística y la semiótica: la teoría del discurso, la narratividad, la teoría de la recepción y la semiótica del texto. Esas categorías, proyectadas en el área de la hermenéutica jurídica, permiten disolver buena parte de los problemas que los juristas discuten desde hace ya muchas décadas. [...] Por cierto, con diferentes formas de organicidad, lo que sucede en EEUU se repite en Europa y en América Latina. (Cárcova, Price, Ruiz, 2014, p. IV)

Certamente a imaginação literária, que exalta emoções e sentimentos, deve impregnar, mas sem substituir, as regras que determinam o raciocínio jurídico e moral, como bem refere Nussbaum (1997, p. 3637). Castanheira Neves (2003), valendo-se de Segre (1989, p. 57-69), quando define narrar como "uma realização linguística mediata que tem por finalidade comunicar a um ou mais interlocutores uma série de acontecimentos, de moda a fazê-los tomar parte no conhecimento deles, alargando assim o seu contexto pragmático", afirma que para tanto pressupõe-se e traduz-se "um certo saber (que não se reduz à ciência, nem mesmo ao conhecimento denotativo-objectivo) no contexto de uma certa experiência comum ou sócio-cultural, de uma certa práxis humana compartilhada, que convoca concretamente um particular modo comunicativo e seja ou não associado a uma pessoal legitimação do narrador" (Castanheira Neves, 2003, p. 370). Assim, narrar já é um exemplum ou um sentido paradigmático (assim nos mitos e nas 
parábolas), uma interpretação, por reconstrução, da realidade e da vida (assim na função literária) (Castanheira Neves, 2003, p. 370-371) ${ }^{16}$.

\section{PRIMEIRO CONSTRUIR MUNDOS, DEPOIS CONTAR HISTÓRIAS: AS RELAÇÕES ENTRE LINGUAGEM E PODER E AS CONTRIBUIÇÕES DOS ESTUDOS EM DIREITO \& LITERATURA}

A aproximação entre direito e literatura evidencia o papel que os produtos culturais desses dois campos desempenham na construção social da realidade, o modo como neles vem impresso e expresso o imaginário social e o quanto a atribuição de sentido a esses produtos culturais encontra-se atrelada às práticas comunicativas, sendo, portanto, objeto de constantes re-interpretações.

Esses pressupostos servem de base para investigar as contribuições que os estudos em direito e literatura - mais especificamente, da matriz direito como literatura - podem fornecer para a compreensão da Constituição a partir de seu estatuto de ficção fundadora, bem como para refletir sobre as condições e os limites de interpretação do texto constitucional, considerado a partir de um filtro de narratividade.

0 primeiro aspecto a ser examinado envolve a relação entre linguagem e poder, perceptível na força que a palavra adquire tanto na recitação mítica e ritualística das sociedades arcaicas ${ }^{17}$ quanto nas fake news aceleradamente difundidas pelas mídias e redes sociais na era da informação ${ }^{18}$.

Assim, as primeiras manifestações do poder da linguagem podem ser identificadas nos mitos cosmogônicos, servindo de ilustração o processo de criação do mundo da tradição judaico-cristã, que é narrado no Gênesis: "No princípio, Deus criou os céus e a terra. A terra estava informe e vazia; as trevas cobriam o abismo e o Espírito de Deus pairava sobre as águas. Deus disse: "Faça-se a luz!” E a luz foi feita” (Gênesis 1:1-3).

Na mitologia judaico-cristã, é nomeando - ou seja, é fazendo uso da linguagem - que Deus cria o mundo e os seres que o habitam. Depois, Deus concede ao homem o domínio sobre todos os animais ${ }^{19}$ e a ele delega a 
tarefa de nomeá-los ${ }^{20}$. Assim, tendo sido criado à imagem e semelhança de Deus, o ser humano é investido de poder e provido de linguagem.

As manifestações da relação linguagem-poder, entretanto, não se limitam às esferas mítica ou religiosa, sendo facilmente detectáveis, seja nas produções literárias ${ }^{21}$, seja no desenvolvimento da filosofia grega. Veja-se, por exemplo, a concepção aristotélica: a conceituação do ser humano como zôon logikón ${ }^{22}$ - animal que fala, animal dotado de linguagem - é condição para a noção de zôon politikón ${ }^{23}$, ou seja, do homem como animal político ${ }^{24}$.

De fato, no Livro I, Capítulo II, de sua Política, Aristóteles (1962) destaca que, entre todos os animais, só ao ser humano foi concedido o uso da palavra [lógos]. De tal modo que, se outros animais também são capazes de emitir sons para exprimir prazer ou dor, apenas o homem é dotado de discurso [lógos] e sabe discernir o bem e o mal, o justo e o injusto, além de outros sentimentos da mesma ordem, sendo a posse e o compartilhamento de tais sentimentos, bem como a livre submissão ao lógos codificado em leis justas, determinantes para a constituição da família e o Estado.

Assim, a partir da concepção aristotélica, a cultura clássica grega

Elabora uma imagem do homem na qual são postos em relevo dois traços fundamentais: o homem como animal que fala e discorre (zoon logikón) e o homem como animal político (zoon politikón). Esses dois traços estão, de resto, em estreita correlação, pois só enquanto dotado do logos o homem é capaz de entrar em relação consensual com seu semelhante e instituir a comunidade política (VAZ, 2004, p. 20).

Nesse sentido, vale lembrar - retornando às imagens da cultura judaico-cristã - o episódio bíblico da Torre de Babel $^{25}$ : além da oferecer a explicação mítica para a origem de diversas línguas, ilustra bem a impossibilidade da constituição da sociedade na ausência de uma língua compartilhada - o que corresponderia, na concepção aristotélica, à impossibilidade de uma vida política (bios politikós), que pressupõe também um sistema de valores partilhado e é exercida pela "livre submissão ao logos codificado em leis justas” (VAZ, 2004, p. 21). 
Algo de novo pode ser vislumbrado, a partir daqui, na relação linguagem-poder. Como visto, há o poder da linguagem, que cria mundos e sociedades, poder constituinte e instituinte - essencial, frise-se, para a narrativa literária, como destaca Umberto Eco, que ao abordar o romance como fato cosmológico afirma: “Entendo que para contar é necessário primeiramente construir um mundo" (1985, p. 21). Mas há, também, a linguagem do poder, que transparece no lógos codificado em leis.

A esse respeito, Alberto Vespaziani alerta que "o direito é a linguagem do poder" (2015, p. 69) e, ao refletir sobre as relações entre linguagem e poder - considerando os âmbitos da literatura e do direito -, chega à seguinte constatação: enquanto, no caso da literatura, a linguagem é um instrumento de criação; no caso do direito, "em especial do direito constitucional, [a linguagem] surge quer como instrumento de disciplina e controle do poder quer como instrumento a serviço das tendências destruidoras do poder" (VESPAZIANI, 2015, p. 70). Daí a importância do diálogo entre direito e literatura, entre direito e semiótica, entre direito e linguística, para apurar a reflexão tanto sobre os limites da linguagem quanto sobre os limites da interpretação, que, por sua vez, incide sobre os limites do poder.

Se o primeiro aspecto que foi objeto de exame dizia respeito à relação linguagem-poder, o segundo aspecto remete à compreensão de que é através da linguagem colocada a serviço de uma narrativa imaginária que tanto a literatura quanto o direito colaboram para a construção da identidade.

Não há mundo sem linguagem. É através da linguagem que o direito se manifesta. A linguagem constrói e representa nossas experiências no mundo e nossa realidade. Ela não representa o mundo social, mas o constitui na trama das relações sociais e intersubjetivas, é construtora dos sentidos produzidos sobre algo. Não há algo exterior ou anterior à própria linguagem, assim como não há uma entidade externa da qual a linguagem seria mera representação. Os significados não são um a priori, não são dados, mas negociados - de modo intersubjetivo e dialógico nas relações sociais, situadas em um contexto sócio-político-histórico (BAKHTIN, 2003). 
Assim, importa explicitar a relação entre literatura, linguagem e construção da identidade. Ao analisar as peculiaridades que fazem da literatura um bem imaterial, Umberto Eco (2011) elenca as funções que ela assume tanto na vida do indivíduo quanto na vida em sociedade. Três delas interessam aqui: (1) a literatura contribui para a formação da língua e da identidade nacional; (2) a leitura de obras literárias nos obriga ao exercício de fidelidade e de respeito aos limites da liberdade de interpretação; (3) o mundo da literatura nos oferece um modelo imaginário de verdade, uma verdade literal que corresponde às denominadas verdades hermenêuticas, pois "o mundo da literatura é um universo no qual é possível fazer testes para estabelecer se um leitor tem o sentido da realidade ou [se ele] é presa de suas próprias alucinações" (ECO, 2011, p. 15).

Em sua enumeração, Eco começa pela incomparável importância da literatura para a formação da língua e afirma que a literatura, "contribuindo para formar a língua, cria identidade e comunidade" (ECO, 2011, p. 11) ${ }^{26}$. Já Stuart Hall - em A identidade cultural na pósmodernidade - aborda a importância das narrativas para a identidade cultural, salientando que as culturas nacionais são compostas por instituições, símbolos e representações, e destaca que a identidade nacional é uma comunidade imaginada ${ }^{27}$, pois

Uma cultura nacional é um discurso - um modo de construir sentidos que influencia e organiza tanto nossas ações quanto a concepção que temos de nós mesmos. [...] As culturas nacionais, ao produzir sentidos sobre "a nação", sentidos com os quais podemos nos identificar, constroem identidades. Esses sentidos estão contidos nas estórias que são contadas sobre a nação, memórias que conectam seu presente com seu passado e imagens que dela são construídas (1999, p. 50-51, grifos no original).

Ora, se literatura e direito colaboram para a construção da identidade social - e, nesse sentido, impõe-se considerar que a identidade nunca é algo acabado, como ensina a psicanálise, daí a conceituação de processos identificatórios ${ }^{28}$-, se tanto no direito quanto na literatura transparece o imaginário social e se os textos literários e jurídicos são igualmente suscetíveis à interpretação, há uma distinção que se mostra 
fundamental: a má interpretação, a interpretação equivocada, fantasiosa e solipsista de um texto literário não tem as mesmas consequência que no caso de um texto jurídico e, em especial, no caso da atribuição de sentido à Constituição

Frise-se que a interpretação é o foco das outras funções da literatura elencadas por Umberto Eco e referidas acima: os textos literários exercitam a compreensão dos limites da interpretação e aprimoram o sentido de realidade do leitor, restringindo as possibilidades de distorções e de devaneios interpretativos.

Chega-se, assim, ao terceiro e último aspecto. Considerando o poder da linguagem de criar identidades nacionais, é fácil reconhecer o caráter fundacional das Constituições. Mas seria correto atribuir-lhes o estatuto de ficção fundadora e, mais do que isso, em que medida tal compreensão favoreceria a reflexão sobre as condições e os limites de interpretação do texto constitucional.

Para compreender (e aceitar) a ficcionalidade do Direito ${ }^{29}$, é preciso abdicar da oposição ficção-realidade, que remonta a Platão (2006) e que, incorporada à tradição ocidental, ainda hoje tende a prevalecer no senso comum.

Nesse sentido, mostra-se interessante e profícuo evocar a revisão que os mitólogos realizaram, no início do séc. XX, ao problematizarem o conceito tradicional de mito, desarticulando-o da ideia de "histórias falsas" e privilegiando a função social que ele desempenha nas sociedades arcaicas.

Constrói-se, assim, como destaca Mircea Eliade em seu Mito $e$ realidade, a concepção de que "o mito narra como [...] uma realidade passou a existir. É sempre, portanto, a narrativa de uma criação: ele relata de que modo algo foi produzido e começou a ser" (1983, p. 17). A existência do mundo comprova que o mito cosmogônico é verdadeiro, ou seja, o mito conta uma história verdadeira porque se refere sempre a realidades.

Nas complexas sociedade contemporâneas, não teriam as constituições esse estatuto de relato das origens; e, no caso da Constituição de 88, não seria ela a narrativa instituinte do Estado Democrático de Direito no Brasil? 
No entanto, ao atribuir caráter mítico, fundador, às constituições, não se estaria correndo o risco de cristalizá-las e, assim, desconsiderar as mudanças sociais que necessitam ser contempladas pelo Direito?

O modo como o mito opera no tempo cíclico que rege as sociedades arcaicas é compatível com a concepção de tempo histórico, do tempo irreversível, que domina as sociedades contemporâneas?

Talvez, compreender a lógica temporal que o mito impõe ao homem das sociedades arcaicas possa ser útil para se pensar a atividade hermenêutica, uma vez que, para ele, não se trata tão-somente de rememorar a história mítica, mas de reatualizá-la, sem nunca perder de vista seu sentido primordial.

No campo literário, a corrente teórica denominada Estética da recepção introduz a concepção de que um texto existe apenas como "mera virtualidade", tal qual defende Wolfgang Iser (1989; 1999), cabendo ao leitor produzir e atribuir sentido. 0 leitor desempenharia, assim, o papel de co-enunciador ${ }^{30}$, ele não só preenche as omissões e lacunas do texto, como, também, o atualiza.

No entanto, paralelamente a essa autonomia do leitor diante do texto, há a necessária congruência entre a expressão do autor - destaque-se, a expressão do autor, não a intenção do autor - e o sentido atribuído ao texto pelo leitor, o que limita sua atuação no campo hermenêutico.

Assim, não se trata de buscar exclusivamente qual o sentido imanente ao texto (voluntas legis), quer o sentido original que o autor a ele teria atribuído (voluntas legislatoris). Tampouco se trata de outorgar ao leitor o privilégio e a liberdade de definir o sentido do texto.

Uma alternativa razoável seria contemplar a tríade autor-textoleitor ou, melhor, legislador-texto-intérprete, que possibilita superar os impasses e as deficiências de concepções interpretativas excludentes - que fixam a busca pelo sentido seja na intenção do autor, seja no sentido implícito ao texto, seja, ainda, na percepção do leitor -, pois propicia a articulação entre os contextos históricos do autor e do leitor, ao mesmo tempo que observa os limites interpretativos fornecidos pelo próprio texto ${ }^{31}$.

Daí a possibilidade de o direito, atuando nos limiares passado-presente e presente-futuro, cumprir a dupla função que Carlos Cárcova aponta: 
El derecho, en lo sustancial, cumple un rol formalizador y reproductor de las relaciones sociales establecida, y a la vez un rol en la remoción y transformación de tales relaciones. Cumple a la vez, una función conservadora y reformadora. Esta aparente contradicción se resuelve en la medida que se rescata para el análisis, el rol de la ideología y concepción relacionista del poder (2009, p. 139).

A proposta de que a interpretação constitucional considere tais limiares aproxima a lógica temporal intrínseca às narrativas fundadoras e a ao seu estatuto de narrativa fundadora e a noção de temporalidade em Heidegger: o passado é tudo menos o que já passou, é algo a que eu posso voltar sempre de novo. A partir do conceito de Ek-stase e da articulação das dimensões passado-presente-futuro tem-se a ideia de que o passado, que vigora por já ter sido e que, como ainda vive, perpassa o presente, forçando-o a se atualizar e a se abrir para o horizonte a ser ultrapassado no futuro, que, ao ser projetado, já chegou.

Por fim, é impossível não destacar que, enquanto o direito operar com construções teóricas que ignoram o linguistic turn e o narrative turn, persistirá a dificuldade de equacionar as paradoxais funções conservadora e reformadora indicadas por Carlos Cárcova, dificuldade que só poderá ser superada com a compreensão de que o direito é linguagem e que, enquanto tal, impõe-se a análise das ideologias em jogo e das relações de poder.

\section{CONSIDERAÇÕES FINAIS: A CONSTITUIÇÃO BRASILEIRA AINDA É POSSÍVEL?}

Passados já trinta anos da promulgação da Constituição de 1988, no contexto de um constitucionalismo contemporâneo submetido a constrangimentos difusos causados pelo descentramento do Estado e do direito, questionar se a Constituição brasileira ainda é possível apresentase como algo que necessariamente se impõe.

Se assumirmos a construção do Estado como ente imaginário e, como tal, permanente, mas sempre cambiante, ao longo da evolução do pensamento político, vamos através da linguagem construir a Constituição 
fundadora do constitucionalismo contemporâneo e, consequentemente, do próprio Estado Democrático de Direito.

Essa conclusão fragiliza, senão fissura, aquela compreensão dos bancos acadêmicos, provocada pelo hiato entre teoria-prática, de que o direito origina-se do fato. Assumida a matriz direito-literatura, especialmente na sua vertente Direito como literatura, é correto discordar dessa máxima, substituindo-a pela compreensão de que é da linguagem e, portanto, da narrativa, que o direito nasce. Mas não só. Não de uma qualquer narrativa. As escolhas das narrativas possíveis, suas tramas e intrigas são necessariamente, no imaginário político-jurídico-social, discutidas, ensaiadas até a estreia. Estado e Constituição, Direito e Literatura, Poder e Linguagem - imaginários que compartilham o mesmo destino - constituem um filtro de narratividade.

No entanto, em tempos de ataques ao constitucionalismo contemporâneo e da necessidade de blindagem às discricionariedades e ativismos judiciais, que interrompem e rompem com as narrativas fundadoras, eliminando ou contaminando o filtro de narratividade, a literatura - assim como a linguagem - não podem ser reduzidas a mero ornamento. A ideia da Constituição folha de papel está aqui presente. Ela só não funda a Constituição real. No entanto, se a literatura (e a linguagem) não refuta(m) uma verdade estabelecida (o poder), ela semeia a possibilidade de multiplicar narrativas possíveis, evidenciando sentidos improváveis, incertos ou enriquecidos, de certo constitucionalismo, a partir de um filtro de narratividade.

\section{NOTAS}

1 A expressão constitucionalismo contemporâneo foi cunhada por Lenio Streck (2017a), em Verdade e consenso, para referir o fenômeno que surge no segundo pós-guerra. 0 constitucionalismo contemporâneo opõe-se às teorias neoconstitucionalistas e propõe um redimensionamento na práxis político-jurídica a partir da teoria do Estado e da Constituição, com o advento do Estado Democrático de Direito, bem como a partir da teoria do Direito, com a reformulação da teoria das fontes, da teoria da norma, da teoria da interpretação e da teoria da decisão (enquanto blindagem às discricionariedades e aos ativismos). Sobre o tema, ver Streck (2017a; 2017b).

2 Nesse sentido, recorra-se ao verbete "constitucionalismo" do Dicionário de política (BOBBIO; MATTEUCCI; PASQUINO, 2000, p. 246-258), bem como aos verbetes "constitucionalismo contemporâneo" e "neoconstitucionalismo" do Dicionário de hermenêutica (STRECK, 2017b, p. 43-47; 206-210). 
3 Toda a construção da presente reflexão parte da premissa de que não há um constitucionalismo, mas, sim, vários constitucionalismos (inglês, americano, francês), na esteira do que defende J. J. Canotilho (2003). Sendo assim, compreende-se o constitucionalismo como um movimento com corações nacionais diversos, que podem ou não se aproximar em alguns pontos, formando uma complexa tessitura histórico-cultural. Nesse sentido, recomenda-se examinar a obra de J. J. Canotilho (2003). Por óbvio, as reflexões aqui expostas são possíveis no contexto dos Estados ocidentais após as Revoluções do século XVIII e a partir da noção de contratualismo fundado em Hobbes, Locke e Rousseau.

4 Há vasta bibliografia sobre o tema, não obstante, com abordagem bastante oportuna para o contexto jurídico atual, especialmente para o cenário brasileiro pós-manifestações de 2013, recomenda-se o artigo "Constituição radical: uma ideia e uma prática" de Vera Karam de Chueiri (2013).

5 Nesse aspecto, recomenda-se exame dos verbetes do Dicionário de hermenêutica (STRECK, 2017b, p. 43-47; 206-210). Sobre o neoconstitucionalismo, ver Michel Carbonell (2007). Ver também Streck e Trindade (2011).

6 Nesse sentido, interessante a contribuição de Pepê (2016) e Ost (2017).

7 Para melhor compreensão do sentido dessa plurisubjetividade do poder constituinte, parece adequado buscar apoio no conceito de polifonia de Mikhail Bakhtin, desenvolvido, na teoria da decisão, por Trindade e Karam (2019).

8 Para o enfrentamento mais profundo sobre o tema, recomenda-se ver Canotilho (2003), bem como Hespanha (2009).

9 Sobre a formação do Estado moderno, sugere-se Heller (1990); Bolzan de Morais e Streck (2019). Nesse mesmo sentido, ver Espindola e Cunha (2011).

10 Vale-se aqui da proposta do romance em cadeia de Ronald Dworkin (2003), quando compara a tarefa do intérprete à escrita de um romance coletivo. Deste modo, toda a jurisdição constitucional, tanto quanto a sequencia de Emendas Constitucionais, compõem uma narrativa - que garante a coerência e a integridade do direito - que a todo instante refunda a Constituição, permitindo que novas narrativas sejam possíveis, sempre num contexto de controle de profusão de sentidos e a partir de uma atividade interpretativa incessante.

11 Para uma compreensão sobre o surgimento, a evolução e a expansão do estudo de matriz direito-literatura no Brasil, ver Trindade (2017). Ver também Streck e Karam (2018).

12 Trata-se de texto não publicado até o momento, intitulado "Salvamento de náufragos - a constitución como ficción fundadora: ¿ruinas circulares?", apresentado em novembro de 2018, no VII Colóquio Internacional de Direito e Literatura, na UFMG.

13 La femme de trente ans, que foi escrita entre 1829 e 1842, tematiza problemas fundamentais da vida amorosa e sentimental das mulheres de 30 anos da época, a partir das angústias e dilemas da protagonista, Julie d'Aiglemont.

14 Quarto de despejo: diário de uma favelada foi escrita em 1960 e constitui um relato do dia a dia nas comunidades pobres da cidade de São Paulo.

15 Tal distinção vem proposta por Lassalle (2002) na Conferência O que é uma Constituição, proferida na cidade de Berlim, em abril de 1862. Curiosamente, Lassale inicia a conferência referindo que: "Por todos os lados e todas as horas, de manhã, de tarde e de noite, estamos ouvindo falar de Constituição e de problemas constitucionais. Nos jornais, nos círculos, nas tavernas e restaurantes, é este o tema inesgotável de todas as conversas" (2002, p. 37). Apesar da especificidade do contexto político e do hiato temporal superior a 150 anos, a semelhança com a situação que vivemos no Brasil atual é evidente, sobretudo se, atualizando os espaços de discussão, incluirmos as redes sociais entre aqueles citados por Lassalle.

16 Essa ideia destes autores, aplicada a teoria da decisão, fazendo críticas às posturas neoconstitucionalistas e aos ativismos judiciais já foi exploda em Espindola $(2018 ; 2016)$.

17 A esse respeito, ver Mito e realidade, de Mircea Eliade (1983), e Linguagem e mito, de Ernst Cassirer (1992).

18 Veja-se, por exemplo, o efeito produzido pelas fake news nos resultados das últimas eleições presidenciais dos Estados Unidos e do Brasil. Recomenda-se a leitura de Pós-verdade: a nova guerra contra os fatos em tempos de "fake news" (D’ANCONA, 2018), embora a obra apresente algumas ideias que possam ser problematizadas. 
19 "Façamos o homem à nossa imagem e semelhança. Que ele reine sobre os peixes do mar, sobre as aves dos céus, sobre os animais domésticos e sobre toda a terra, e sobre todos os répteis que se arrastem sobre a terra" (Gênesis, 1:26).

20 "Tendo, pois, o Senhor Deus formado da terra todos os animais dos campos, e todas as aves dos céus, levou-os ao homem, para ver como ele os havia de chamar; e todo o nome que o homem pôs aos animais vivos, esse é o seu verdadeiro nome" (Gênesis, 2: 19).

21 A referência explícita ao poder das palavras inspiradas pelas Musas está presente tanto em $\mathrm{He}$ síodo quanto em Homero. Sobre o poder numinoso das Musas, consulte o estudo introdutório de Jaa Torrano ao texto de Hesíodo (1991).

220 termo lógikon deriva do vocábulo lógos, tradicionalmente traduzido como razão, lógica, inteligência - por influência do latim (ratio) -, mas que também tem o sentido de palavra, linguagem, fala, discurso. Como destaca Gobry (2007, p. 89-90), “O primeiro sentido de lógos (do verbo légein / $\lambda$ ćgein, falar) é fala, linguagem. Ora, a linguagem é a expressão do pensamento. 0 capítulo IV do tratado aristotélico Da interpretação trata do discurso: lógos".

23 Destaque-se que as palavras politikón (político) e politeía - termo empregado para designar tanto Estado e República quanto Constituição - derivam de pólis, vocábulo que, além de significar Estado, remete à "comunidade urbana à qual convém dar uma Constituição, politeía" (GOBRY, 2007, p. 119).

24 Segundo Henrique de Lima Vaz: “Enquanto ser dotado do logos (da fala e do discurso), o homem transcende de alguma maneira a natureza e não pode ser considerado simplesmente um ser natural. [...] Ele é um zoon politikón por ser exatamente um zoon logikón" (VAZ, 2004, p. 37-38).

25 "E era toda a terra de uma mesma língua e de uma mesma fala. [...] E disseram: Eia, edifiquemos nós uma cidade e uma torre cujo cume toque nos céus, e façamo-nos um nome, para que não sejamos espalhados sobre a face de toda a terra. Então desceu o Senhor para ver a cidade e a torre que os filhos dos homens edificavam; E o Senhor disse: Eis que o povo é um, e todos têm uma mesma língua; e isto é o que começam a fazer; e agora, não haverá restrição para tudo o que eles intentarem fazer. Eia, desçamos e confundamos ali a sua língua, para que não entenda um a língua do outro. Assim o Senhor os espalhou dali sobre a face de toda a terra; e cessaram de edificar a cidade" (Gênesis 11:1-8).

26 É interessante observar a análise que Eco (2011) oferece para comprovar a vinculação entre literatura e identidade nacional, referindo a consolidação do vulgar dantesco como língua falada por todos e a unificação política da Itália.

27 A expressão é adotada de Benedict Anderson (1983).

28 A concepção de processos identificatórios se contrapõe à ideia de identidade como algo fixo e imutável. É na obra Psicología de las masas y análisis del yo, que S. Freud (1981) define identificação, estabelece suas três modalidades e discorre sobre os modos como os processos identificatórios operam.

29 Inúmeros são os trabalhos de José Calvo González que abordam a ficcionalidade do direito: Derecho y narración (1996); Verdad [narración] justicia (1998); La justicia como relato (2002). Destaca-se, no entanto, a tese defendida no VI CIDIL: "Nada no direito é extraficcional" (CALVO GONZÁLEZ, 2018).

30 A designação co-enunciador, proposta por A. Culioli e referida por D. Maingueneau (1996), remete à participação do receptor na produção de sentido do enunciado.

31 Tal modelo opera com o conceito de horizonte de sentido (HUSSERL, [s.d.]; GADAMER, 2003). Para aprofundar a compreensão do modelo, ver Karam (2017a; 2017b). 


\section{REFERÊNCIAS}

ANDERSON, Benedict. Imagined communities. Londres: Verso, 1983.

ARISTOTE. La politique. Trad. de J. Tricot. Paris: Vrin, 1962. v. 1.

ARISTÓTELES. Arte poética. In: ARISTÓTELES; HORÁCIO; LONGINO. A poética clássica. Trad. de Jaime Bruna. São Paulo: Cultrix, 1997. p. 19-52.

BAKHTIN, Mikhail. Estética da criação verbal. Trad. Paulo Bezerra. São Paulo: Martins Fontes, 2003.

BALZAC, H. Mulher de 30 anos. São Paulo, SP: L\&PM Editores, 1998.

BOBBIO, N.; MATTEUCCI, N.; PASQUINO, G. Dicionário de política. v. 1. Brasília, DF: Universidade de Brasília, 2000.

BOLZAN DE MORAIS, José Luis. STRECK, Lênio Luiz. Ciência política e teoria do estado. 8. ed. Porto Alegre: Livraria do Advogado, 2019.

CALVO GONZÁLEZ, José. Derecho y narración: materiales para una teoria y crítica narrativista del Derecho. Barcelona: Ariel, 1996.

CALVO GONZÁLEZ, José. La justicia como relato. Málaga: Ágora, 2002.CASSIRER, Ernst. Linguagem e mito. Trad. de J. Ginzburg e Miriam Schnaiderman. São Paulo: Perspectiva, 1992.

CALVO GONZÁLEZ, José. Nada no direito é extraficcional (escritura, ficcionalidade e relato como ars iurium). In: TRINDADE, André Karam; KARAM, Henriete (Ed.). Por dentro da lei: direito, narrativa e ficção. Florianópolis: Tirant lo blanch, 2018. p. 13-32.

CALVO GONZÁLEZ, José. Verdad [narración] justicia. Málaga: Universidad de Málaga, 1998.

CANOTILHO, J. J. G. Direito constitucional e teoria da constituição. 7. ed. Coimbra: Almedina, 2003. 
CARBONELL, Miguel. El neoconstitucionalismo en su laberinto. In: CARBONELL, Miguel. Teoría del neoconstitucionalismo. Ensayos escogidos. Madrid: Trotta, 2007.

CÁRCOVA, C. M.; PRICE, J. E. D.; RUIZ, A. E. C. Estudios sobre el derecho y la literatura. 1. ed. Buenos Aires: Infojus, 2014.

CÁRCOVA, Carlos M. Las teorías jurídicas post positivistas. Buenos Aires: Abeledo Perrot, 2009.

CASSIRER, Ernst. Linguagem e mito. Trad. de J. Ginzburg e Miriam Schnaiderman. São Paulo: Perspectiva, 1992.

CASTORIADIS, Cornelius. A instituição imaginária da sociedade. 5. ed. Rio de Janeiro: Paz e Terra, 2000.

CHUEIRI, V. K. de. Constituição radical: uma ideia e uma prática, Revista da Faculdade de Direito UFPR, v. 58, p. 25-36, 2013.

D’ANCONA, Matthew. Pós-verdade: a nova guerra contra os fatos em tempos de fake news. Trad. de Carlos Szlak. Barueri: Faro Editorial, 2018.

DWORKIN, Ronald. 0 império do direito. Trad. Jefferson Luiz Camargo. Revisão técnica Gildo Sá Leitão Rios. $2^{\underline{a}}$ tiragem. 1ํㅡㄹ. ed. São Paulo: Martins Fontes, 2003.

ECO, Umberto. Pós-escrito a “0 nome da rosa”. Trad. de Letizia Zini Antunes e Álvaro Lorencini. Rio de Janeiro: Nova Fronteira, 1985.

ECO, Umberto. Sobre a literatura. Trad. de Eliana Aguiar. Rio de Janeiro: BestBolso, 2011.

ELIADE, Mircea. Mito y realidad. Trad. de Luis Gil. Barcelona: Labor, 1983.

ESPINDOLA, Angela Araújo da Silveira. A teoria da decisão e o homem que confundiu a mulher com um chapéu. Anamorphosis - Revista Internacional de Direito e Literatura, v. 4, n. 2, p. 595-614, dez. 2018. Doi: http://dx.doi. org/10.21119/anamps.42.595-614. 
ESPINDOLA, Angela Araújo da Silveira. Entre a insustentabilidade e a futilidade: a jurisdição, o direito e o imaginário social sobre o juiz. Anamorphosis - Revista Internacional de Direito e Literatura, v. 2, n. 2, p. 293-320, dez. 2016. Doi: http://dx.doi.org/10.21119/anamps.22.293-320.

ESPINDOLA, Angela Araujo; CUNHA, Guilherme Cardoso Antunes da. O processo, os direitos fundamentais e a transição do estado liberal clássico para o estado contemporâneo. Revista de Estudos Constitucionais, Hermenêutica e Teoria do Direito, v. 3, n. 1, p. 84-94, 2011.

FREUD, Sigmund. Psicología de las masas y análisis del yo. In: FREUD, Sigmund. Obras completas. 4. ed. Madrid: Biblioteca Nueva, 1981. p. 2563-2610.

GADAMER, Hans-Georg. Verdade y método, I. Trad. de Ana Agud Aparicio e Rafael de Agapito. 10. ed. Salamanca: Sígueme, 2003.

GOBRY, Ivan. Vocabulário grego da filosofia. Trad. de Ivone C. Benedetti. São Paulo: Martins Fontes, 2007.

HALL, Stuart. A identidade cultural na pós-modernidade. Trad. de Tomaz Tadeu da Silva e Guacira Lopes Louro. 3 ed. Rio de Janeiro: DP\&A Editora. 1999.

HEIDEGGER, Martin. 0 conceito de tempo. Trad. de Irene Borges-Duarte. Lisboa: Fim de século, 2003.

HELLER, Herman. Teoria del estado. Tradução de Luís Tobío. Buenos Aires: Fondo de Cultura Económica, 1990.

HESÍODO. Teogonia: a origem dos deuses. Estudo e tradução de Jaa Torrano. São Paulo: Iluminuras, 1991.

HESPANHA, A. M. Hércules confundido: sentidos improváveis e incertos do constitucionalismo oitocentista: o caso português. Curitiba, PR: Juruá, 2009.

HUSSERL, Edmund. Meditações cartesianas: introdução à fenomenologia. Trad. de Maria Gorete Lopes e Sousa. Porto: Rés, [s. d.]. 
ISER, Wolfgang. El proceso de lectura. Una perspectiva fenomenológica. In: WARNING, Rainer (Coord.). Estética de la recepción. Trad. de Ricardo Sánchez Ortiz de Urbina. Madri: Visor, 1989. p. 149-164.

ISER, Wolfgang. O que é antropologia literária? In: ROCHA, João Cezar de Castro (Org.). Teoria da ficção: indagações à obra de Wolfgang Iser. Trad. de Bluma Waddington Vilar. Rio de Janeiro: Ed. UERJ, 1999. p. 147-178.

JESUS, C. M. DE. Quarto de despejo: Diário de uma favelada. São Paulo, SP: Ática, 2014.

KARAM, Henriete. 0 direito na contramão da literatura: a criação no paradigma contemporâneo. Revista Eletrônica do Curso de Direito da UFSM, v. 12, n. 3, p. 1022-1043, 2017b. Doi: http://dx.doi.org/10.5902/1981369429566.

KARAM, Henriete. Questões teóricas e metodológicas do direito na literatura: um percurso analítico-interpretativo a partir do conto "Suje-se gordo!", de Machado de Assis. Rev. direito GV, v. 13, n. 3, p. 827-865, 2017a. Doi: http:// dx.doi.org/10.1590/2317-6172201733.

KARAM, Henriete. STRECK, Lenio Luiz. A literatura ajuda a existencializar o direito. ANAMORPHOSIS-Revista Internacional de Direito e Literatura, v. 4, n. 2, p. 615-626, 2018.

LASSALE, Ferdinand. 0 que é uma Constituição? Trad. Hiltomar Martins Oliveira. Belo Horizonte: Ed. Líder, 2002.

MAINGUENEAU, Dominique. Pragmática para o discurso literário. Trad. de Marina Appenzeller. São Paulo: Martins Fontes, 1996.

NUSSBAUM, M. Justiça Poetica. Barcelona: Editorial Andres Bello, 1997.

OST, François. [Entrevista com François Ost]. Direito e Literatura: os dois lados do espelho. ANAMORPHOSIS-Revista Internacional de Direito e Literatura, v. 3, n. 1, p. 259-274, 2017.

PÊPE, Albano Marcos Bastos. Direito e literatura: uma intersecção possível? Interlocuções com o pensamento waratiano. Anamorphosis: Revista Internacional de Direito e Literatura, v. 2, n. 1, p. 5-15, 2016. 
PLATÃO. A república. São Paulo, SP: Martins Fontes, 2006.

ROTH, André-Noël. 0 direito em crise: fim do estado moderno? In: FARIA, José Eduardo. Direito e globalização econômica: implicações e perspectivas. São Paulo: Malheiros Editores, 1996.

SHELLEY, Percy Bysshe. Uma defesa da poesia e outros ensaios. Trad. Fabio Cyrino e Marcella Furtado. São Paulo: Landmarck, 2008.

STRECK, L. L. Dicionário de hermenêutica: quarenta temas fundamentais da teoria do direito à luz da crítica hermenêutica do Direito. Belo Horizonte, MG: Letramento, 2017b.

STRECK, L. L. Verdade e consenso: constituição, hermenêutica e teorias discursivas: da possibilidade à necessidade de respostas corretas em direito. 6 . ed. São Paulo: Saraiva, 2017a.

STRECK, Lenio Luiz; TRINDADE, André Karam. Contra o neoconstitucionalismo. Constituição, Economia e Desenvolvimento: Revista da Academia Brasileira de Direito Constitucional, n. 4, 2011.

TRINDADE, André Karam; BERNSTS, Luísa Giuliani. O estudo do" direito e literatura" no Brasil: surgimento, evolução e expansão. ANAMORPHOSIS Revista Internacional de Direito e Literatura, v. 3, n. 1, p. 225-257, 2017.

TRINDADE, André Karam; KARAM, Henriete. Polifonia e verdade nas narrativas processuais. Seqüência: Estudos Jurídicos e Políticos, Florianópolis, v. 39, n. 80, p. 51-74, jan. 2019. ISSN 2177-7055. Disponível em: https://periodicos.ufsc.br/ index.php/sequencia/article/view/2177-7055.2018v39n80p51. Acesso em: 07 set. 2019. doi:https://doi.org/10.5007/2177-7055.2018v39n80p51

VAZ, Henrique C. de Lima. Antropologia filosófica. São Paulo: Loyola, 2004.v. 1.

VESPAZIANI, Alberto. 0 poder da linguagem e as narrativas processuais. Anamorphosis - Revista Internacional de Direito e Literatura, v. 1, n. 1, p. 69-84, jan.-jun. 2015. Doi: http://dx.doi.org/10.21119/anamps.11.69-84. 
Recebido em: 9-12-2019

Aprovado em: 16-12-2019

\section{Henriete Karam}

Doutora em Estudos Literários, pela Universidade Federal do Rio Grande do Sul (UFRGS); mestre em Teoria da Literatura, pela Pontifícia Universidade Católica do Rio Grande do Sul (PUCRS); professora de Hermenêutica Jurídica no Programa de Pós-Graduação em Direito da Faculdade Guanambi (FG); professoracolaboradora, do Programa de Pós-Graduação em Letras da Universidade Federal do Rio Grande do Sul (UFRGS); e professora-convidada da Especialização em Psicanálise da Universidade do Vale do Rio dos Sinos (UNISINOS). Pertence à Rede Brasileira Direito e Literatura (RDL), na condição de Membro-Fundadora e de Editora-Chefe da Anamorphosis - Revista Internacional de Direito e Literatura (Qualis A2), publicação científica da RDL. Permanente ao quadro de professores do Programa Direito \& Literatura (TV Justiça). E-mail: h.karam@terra.com.br

\section{Angela Araujo da Silveira Espindola}

Doutora; mestre em Direito Público (UNISINOS); professora Permanente do Programa de Pós-Graduação em Direito do Centro Universitário de Guanambi (UNIFG/BA); professora Colaboradora do Programa de Pós-Graduação em Direito da Universidade Federal de Santa Maria (UFSM/RS); lider do Grupo de Pesquisa Prhonesis: Jurisdição e Hermenêutica. Membro Fundadora e Vice-Presidente da Rede Brasileira Direito e Literatura (RDL). Advogada e consultora. E-mail: ange. espindola@gmail.com.

Centro Universitário FG - UNIFG

Avenida Pedro Felipe Duarte, 4911 - São Sebastião, Guanambi - BA, 46430-000. 